\title{
The role of preoperative urodynamics in stress urinary incontinence surgery
}

\author{
Duane R. Hickling, $M D^{\prime}$; Stephen S. Steele, $M D^{2}$ \\ 'Division of Urology, Department of Surgery, The Ottawa Hospital, University of Ottawa, Ottawa, ON; '2Queen's University, Kingston, ON; Canada
}

Cite as: Can Urol Assoc J 2017;11 (6Suppl2):S113-5. http://dx.doi.org/10.5489/cuaj.4581

See related commentary on page $\$ 116$.

\section{Abstract}

The routine use of urodynamics prior to incontinence surgery continues to be debated. The evidence available from randomized, control trials suggests that preoperative urodynamics do not improve surgical outcomes and are not cost-effective.

\section{Introduction}

The value of urodynamics (UDS) in patients with stress urinary incontinence (SUI) continues to be debated. The American Urological Association and the Society of Urodynamics and Female Urogenital Reconstruction have stated in their joint UDS guideline that "clinicians may perform multichannel urodynamics in patients with both symptoms and physical findings of stress incontinence who are considering invasive, potentially morbid, or irreversible treatments." ${ }^{1}$ This supplement will review the available evidence pertaining to the use of preoperative UDS in patients considering SUI surgery.

\section{UDS: Best practice}

UDS are a set of interactive diagnostic tests used to assess lower urinary tract function and/or dysfunction. ${ }^{1}$ UDS should be used as an adjunct to the comprehensive evaluation of patients with lower urinary tract symptoms and, according to good practice, should be designed and customized to answer specific questions. ${ }^{2}$ Clinicians should be aware that UDS is operatordependent and that there are other known limitations, including false positive and negative rates of various UDS parameters. In addition, before recommending UDS, clinicians must always consider if the benefits of UDS, such as improved outcomes, will outweigh the potential costs, including embarrassment, pain, urinary tract infection, and the financial burden., ${ }^{2,3}$

\section{Preoperative UDS and SUI surgery outcomes}

Two non-inferiority, multicentre, randomized, controlled trials (RCTs) demonstrate that preoperative UDS do not improve outcomes of stress incontinence surgery.

The Value of Urodynamics prior to Stress Incontinence Surgery (VUSIS) trial allocated 59 women with SUIpredominant incontinence demonstrable on physical examination and/or micturition diary to a workup with or without UDS. Conservative therapy must have failed and surgical treatment needed to be under consideration. This study was closed prematurely secondary to slow recruitment. The primary outcome was clinical reduction of complaints as measured by the Urogenital Distress Inventory (UDI) urinary incontinence subscale 12 months after treatment. The mean difference in improvement on the UDI urinary incontinence scale was 14 in favour of the group without UDS (48, standard deviation [SD] \pm 22 vs. $34, \mathrm{SD} \pm 22$, $95 \%$ confidence interval $[\mathrm{Cl}]-28$ to -0.26$)$, confirming the predetermined non-inferior margin. Five women in the UDS group elected for non-surgical treatment after their study for reasons including detrusor overactivity (DO) $(n=3)$, obesity and mild symptoms $(n=1)$, and patient request $(n=1)$. Three of these five patients eventually had SUI surgery and the authors therefore concluded that preoperative UDS has the risk of delaying effective treatment. ${ }^{4}$

The Value of Urodynamic Evaluation (ValUE) trial randomized 630 women with uncomplicated, demonstrable SUI to undergo preoperative office evaluation with and without UDS. The primary outcome was treatment success at 12 months, defined as a $\geq 70 \%$ reduction in UDI score and a response of "much better" or "very much better" on the Patient Global Impression of Improvement (PGI-I). Treatment success was $76.9 \%$ in the office evaluation and UDS group vs. $77.2 \%$ in the office evaluation-only group (difference, -0.3 percentage points; $95 \% \mathrm{Cl}-7.5$ to 6.9 ), which was consistent with predetermined noninferiority margin of 11 points. There were no differences between groups in a secondary outcome measures, including positive provocative stress testing and changes in UDI, PGI-I, Incontinence 
Severity Index, and quality-of-life measures. Women who had UDS were significantly less likely to receive a diagnosis of overactive bladder and more likely to receive a diagnosis of voiding phase dysfunction. Interestingly, these changes did not lead to significant between-group differences in treatment selection or outcomes and is likely related to the aforementioned limitations of UDS. ${ }^{5}$

In 2014, Rachaneni and Latthe performed a systematic review and meta-analysis asking the question, "Does preoperative UDS improve outcomes for women undergoing surgery for SUI?" The authors identified 388 pertinent articles, but used only three RCTS in their analysis. The VUSIS and ValUE trials were included in this analysis along with data from a small, European, single-centre study abstract. ${ }^{4,6,7}$ There was no statistical difference in the risk ratio (RR) of subjective cure, objective cure, or complications, such as voiding dysfunction or urinary urgency between those with and without preoperative UDS. ${ }^{8}$

\section{Specific UDS parameters as predictors of stress incontinence surgery success}

Addressing the secondary aim of the Stress Incontinence Surgical Treatment Efficacy Trial (SISTEr), Nager et al examined whether the presence of preoperative urodynamic SUI (USI), DO, and the measures of Valsalva leak point pressure (VLPP) could predict continence outcomes. A total of 655 women with demonstrable stress-predominant urinary incontinence were randomized to either Burch colposuspension or autologous rectus fascia pubovaginal sling. Preoperative free uroflowmetry, filling cystometry, and pressure flow studies were performed in all. Overall treatment success required a negative pad test, no urinary incontinence on a three-day diary, a negative stress test, no self-reported SUI symptoms, and no re-treatment for SUI. Stress-specific success required all of the last three criteria. There was a trend (i.e., not statistically significant) for greater odds of overall success in subjects with USI compared with the no USI group (odds ratio [OR] 2.26; 95\% CI 0.99, 5.17). The odds of stress-specific success did not differ by USI status. Subjects with DO did not have significantly worse success rates and stratifying by treatment group, there was no difference in mean VLPP values between surgical successes and failures. In addition, when stratified into low VLPP $(<90$ $\left.\mathrm{cmH}_{2} 0\right)$ vs. high VLPP $\left(>90 \mathrm{cmH}_{2} 0\right)$, stress-specific success rates were similar (55\% vs. $54 \%) .{ }^{9}$

Lemack et al also analyzed data from SISTEr and found that preoperative UDS did not predict postoperative voiding dysfunction, defined as use of a catheter after six weeks postoperatively or the need for a reoperation. ${ }^{10}$

All 597 women randomized to have either a retropubic or transobturator midurethral sling in the Trial of Mid-Urethral
Slings (TOMUS) had preoperative UDS. There were no differences in objective or subjective success rates when the analyses were adjusted for VLPP or maximum urethral closure pressure (MUCP). This suggests that patients with more severe stress incontinence are no more likely to have treatment failure with one type of midurethral sling compared to the other. ${ }^{11}$

\section{Physician confidence and treatment success and UDS costs}

Zimmerin et al performed a planned secondary analysis of the ValUE trial to determine if preoperative UDS affects physicians' diagnostic confidence and if physician confidence affects treatment outcomes at one year. Physician confidence did improve after UDS in patients with baseline SUI (4.52-4.63; $\mathrm{p}<0.005)$, overactive bladder - wet (3.55-3.75; $\mathrm{p}<0.001)$, overactive bladder - dry (3.55-3.68; $\mathrm{p}<0.005)$, voiding dysfunction (3.81-3.95; $\mathrm{p}<0.005)$, and suspected intrinsic sphincter deficiency $(3.63-3.92 ; p<0.001)$. However, increased physician confidence after UDS was not associated with higher odds of treatment success. ${ }^{12}$

The cost of preoperative UDS was determined in another secondary analysis of the ValUE trial. Using national reimbursement rates, the average cost of UDS was estimated to be $\$ 338.3$ USD. Extrapolating this cost to women similar to those enrolled in the ValUE trial, authors determined that \$13-33 million could be saved annually by not performed preoperative UDS. ${ }^{13}$

\section{Conclusion}

The available body of evidence suggests that patients considering SUI surgery with pure SUI or stress-predominant mixed urinary incontinence do not benefit from preoperative UDS. Preoperative UDS does improve clinician confidence in diagnosis, but this ultimately does not translate into improved outcomes and therefore cannot be used to justify the associated risks and financial costs of UDS. However, if after careful office evaluation, questions remain regarding a patient's ability to store or empty urine, UDS may still be considered.

\footnotetext{
Competing interests: Dr. Hickling has been a speaker for Allergan, Astellas, and Pfizer; and has participated in clinical trials supported by Astellas and Ipsen. Dr. Steele has been an advisor for Allergan, Astellas, Fering, and Pfizer; a speaker for Abbott, Astellas, and Pfizer; has received grants from Astellas and Pfizer; and has participated in clinical trials supported by Astellas and Pfizer.
}

This paper has been peer-reviewed. 


\section{References}

1. Winters JC, Dmochowski RR, Goldman HB, et al. Urodynamic studies in adults: AUA/SUFU guideline. J Urol 2012;188 (6 Suppl):2464-72. https://doi.org/10.1016/i.juro.2012.09.081

2. Foon $R$, Toozs-Hobson $P$, Latthe P. Prophylactic antibiotics to reduce the risk of urinary tract infections after urodynamic studies. Foon R, ed. Cochrane Database Syst Rev 2012;10:CD008224. https://doi.org/10.1002/14651858.CD008224.pub2

3. Neustaedter EG, Milne J, Shorten K, et al. How well informed are women who undergo urodynamic testing? Neurourol Urodyn 2011;30:572-7. https://doi.org/10.1002/nau.21014

4. van Leiisen SAL, Kluivers KB, Mol BWJ, et al. Can preoperative urodynamic investigation be omitted in women with stress urinary incontinence? A non-inferiority, randomized, controlled trial. Neurourol Urodyn 2012;31:1118-23. https://doi.org/10.1002/nau.22230

5. Nager CW, Brubaker L, Litman HJ. A randomized trial of urodynamic testing before stress-incontinence surgery. N Engl J Med 2012;366:1987-97. https://doi.org/10.1056/NEJMoal 113595

6. Nager $\mathrm{CW}$, Brubaker L, Litman $\mathrm{HJ}$, et al. A randomized trial of urodynamic testing before stress-incontinence surgery. N Engl J Med 2012;366:1987-97. https://doi.org/10.1056/NEJMoal 113595

7. Romero R, Oyarzun E, Mazor M, et al. Meta-analysis of the relationship between asymptomatic bacteriuria and preterm delivery/low birth weight. Obstet Gynecol 1989;73:576-82.
8. Rachaneni $S$, Latthe P. Does preoperative urodynamics improve outcomes for women undergoing surgery for stress urinary incontinence? A systematic review and meta-analysis. BJOG 2015;122:8-16. https://doi.org/10.1111/1471-0528.12954

9. Nager CW, FitzGerald M, Kraus SR, et al. Urodynamic measures do not predict stress continence outcomes after surgery for stress urinary incontinence in selected women. J Urol 2008;179:1470-4. https://doi.org/10.1016/i.juro.2007.11.077

10. Lemack GE, Krauss $S$, Litman $H$, et al. Normal preoperative urodynamic testing does not predict voiding dysfunction after Burch colposuspension vs. pubovaginal sling. J Urol 2008;180:2076-80. https://doi.org/10.1016/i.juro.2008.07.027

11. Richter HE, Albo ME, Zyczynski HM, et al. Retropubic vs. transobturator midurethral slings for stress incontinence. N Engl J Med 2010;362:2066-76. https://doi.org/10.1056/NEJMo00912658

12. Zimmern $\mathrm{P}$, Litman $\mathrm{H}$, Nager $\mathrm{C}$, et al. Preoperative urodynamics in women with stress urinary incontinence increases physician confidence, but does not improve outcomes. Neurourol Urodyn 2014;33:302-6. https://doi.org/10.1002/nau.22398

13. Norton PA, Nager CW, Brubaker $L$, et al. The cost of preoperative urodynamics: A secondary analysis of the ValUE trial. Neurourol Urodyn 2016;35:81-4. https://doi.org/10.1002/nau.22684

Correspondence: Dr. Duane Hickling, Division of Urology, Department of Surgery, The Ottawa Hospital, University of Ottawa, Ottawa, ON, Canada; dhickling@toh.on.ca 